\title{
Can audit improve antibiotic prescribing in general dental practice?
}

\author{
N. A. O. Palmer, ' Y. M. Dailey, ${ }^{2}$ and M. V. Martin, ${ }^{3}$
}

Objective To investigate whether clinical audit can improve general dental practitioners' prescribing of antibiotics. Design An intervention study carried out in general dental practice in the North West of England.

Method Information was collected over an initial six-week period from 175 general dental practitioners on their current antibiotic prescribing practices. The information collected was the antibiotic prescribed including dose, frequency and duration, the clinically presenting signs and conditions, the medical history (if for prophylaxis), and any other reasons for prescribing. This was compared to the practitioners' antibiotic prescribing for a further six-week period following an audit, which included an educational component and the issuing of guidelines.

Results During the initial period practitioners issued 2316 prescriptions for antibiotics. This was reduced by $42.5 \%$ to 1330 during the audit. The majority of the antibiotics $(81 \%)$ for both periods were prescribed for therapeutic reasons. The most commonly prescribed antibiotics were amoxycillin (57.6\%), metronidazole $(23.8 \%)$, penicillin $(9.3 \%)$, erythromycin $(4.8 \%)$ and a combination of amoxycillin and metronidazole (1.7\%). The antibiotic regimens used by practitioners were significantly changed by the audit $(\mathrm{P}<0.001)$ and there was a significant reduction in the number of prescriptions $(\mathrm{P}<0.05)$ which did not conform to national guidelines.

Conclusions The results from this investigation support the conclusion that clinical audit, with the issuing of guidelines and an educational component, can change prescribing practices leading to a more rational and appropriate use of antibiotics in general dental practice.

Clinical audit was introduced into general dental practice in 1995 and has been defined as the systematic, critical analysis of the quality of dental care, including the procedures and processes used for diagnosis, intervention and treatment, the use of resources and the resulting outcome and quality of life as assessed by both professionals and patients. ${ }^{1}$ The suggested criteria for undertaking an audit are that the issue to be addressed should be a common, significant or serious problem; any changes following audit should benefit patients and lead to greater effectiveness; that the issue is relevant to professional practice and that there is a realistic potential for improvement. ${ }^{2}$

There is evidence that antibiotics are prescribed inappropriately in general dental practice. ${ }^{3-5}$ With the increasing worldwide problem of antimicrobial resistance and the threat to public health, there is a need to rationalise the prescribing of antibiotics. ${ }^{6}$

\footnotetext{
$1^{*}$ Part-time lecturer, ${ }^{2}$ Lecturer, ${ }^{3}$ Senior Lecturer, Department of Clinical Dental Sciences, University of Liverpool, Liverpool L69 3BX

${ }^{*}$ Correspondence to: N. Palmer

REFEREED PAPER

Received 19.10.00; Accepted 17.04.01

(c) British Dental Journal 2001; 191: 253-255
}

Antibiotic use has been the subject of many audits and educational activities within medical practice. ${ }^{7-10}$ In contrast, very few audits on antibiotic prescribing in dental practice have been reported. ${ }^{11,12}$ It has been suggested that the production of guidelines for general dental practitioners (GDPs) along with educational initiatives and audit may encourage safe, effective, rational and economic use of antibiotics and at the same time reduce the likelihood of dentists contributing to the problem of antibiotic resistance. ${ }^{5}$

It has been noted that most audits have focussed on the process, rather than the structure or outcomes. ${ }^{13}$ The aim of this study was to investigate whether clinical audit might change the prescribing of antibiotics by GDPs.

\section{Method}

Subjects

All 932 GDPs working within South Cheshire, North Cheshire, Liverpool, Wirral, Sefton and St Helens and Knowsley Health Authorities in the North West of England were invited to participate in the study. The 175 dentists who took part were divided into groups of eight to ten and were assigned a trained audit facilitator to advise and oversee the investigation and audit.

\section{Data collection}

A pro forma was designed to collect information for each occasion a prescription for antibiotics was issued. The information noted on the pro forma included the antibiotic prescribed, dose, frequency, duration, the clinical signs and presenting condition, the medical history (if for prophylaxis), and any other reasons for prescribing the antimicrobial. No identification of the person completing the pro forma was made.

\section{Procedure}

The study consisted of an initial six-week period of data collection, following which the results were reviewed. Areas of inappropriate prescribing were noted and educational meetings were held for all participants to discuss the results of the data with experts in the field of oral microbiology and antimicrobial prescribing. During these meetings, practitioners were made aware of the principles of appropriate prescribing, both therapeutically and prophylactically, based on the recently published guidelines of the Faculty of General Dental Practitioners, Royal College of Surgeons of England. ${ }^{14}$ All the groups then met individually and set standards for antibiotic prescribing based on the guidelines and the educational component.

Practitioners then audited their antibiotic prescribing for a further six-week period, collecting the information for each prescription issued as described above.

\section{Statistical analysis}

The anonymous pre-audit and audit data were numerically coded and entered into a Statistical Package for Social Sciences (SPSS) database and analysed. ${ }^{15}$ Frequencies were used to examine and describe the distribution of all the variables. Changes in prescribing 


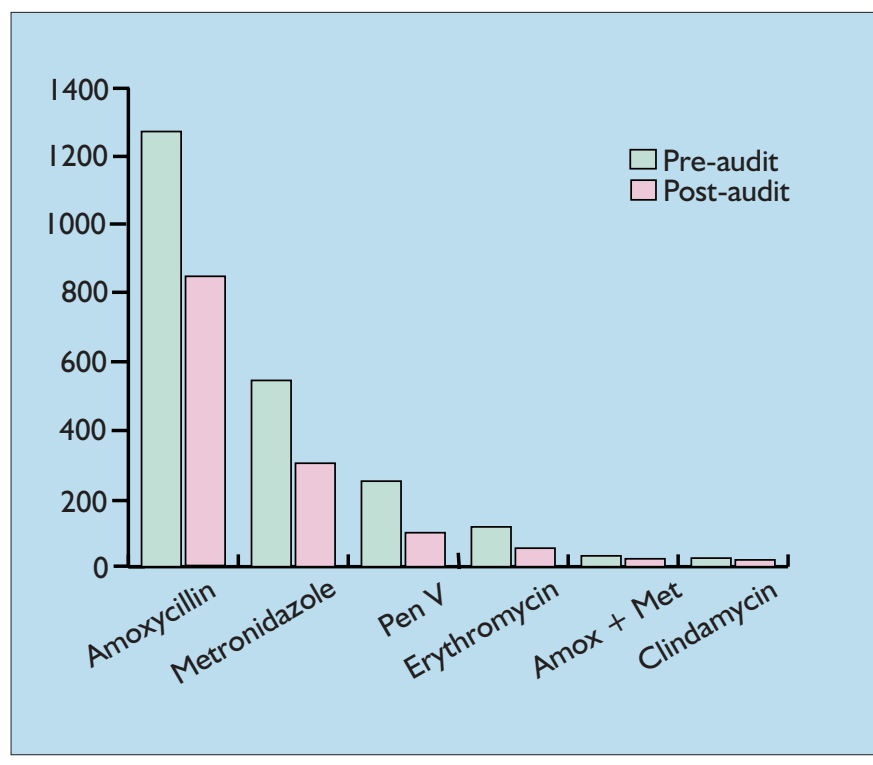

Fig. I Number of prescriptions for each antibiotic issued, pre- and post-audit

practices between the pre-audit and audit periods were tested for significance using the chi-square test.

\section{Results}

The total number of practitioners who took part in the study was 175. During the pre-audit period 2316 prescriptions for antibiotics were issued. This had reduced by $42.5 \%$ to 1330 following the issuing of prescribing guidelines, educational meetings, setting of standards and audit.

\section{Antibiotics prescribed}

The antibiotics prescribed before and after the educational component, issuing of guidelines and audit are shown in Figure 1. Amoxycillin was the most commonly prescribed antibiotic (57.6\%) followed by metronidazole (23.8\%), penicillin (9.3\%), erythromycin $(4.8 \%)$, with a combination of amoxycillin and metronidazole being used in $1.7 \%$ of prescriptions. Clindamycin $(1.4 \%)$ was used primarily in prophylactic doses.

\section{Reasons for prescribing}

The majority of the prescriptions ( $81 \%$ ) over the two six-week periods were issued for therapeutic reasons. Table 1 shows the clinical conditions recorded by GDPs for which antibiotics were prescribed, the number of prescriptions issued before and during audit and the percentage reduction between the two periods. Reductions in the number of prescriptions issued following guidelines and the educational component ranged from $17.3 \%$ to $100 \%$ for the clinical conditions recorded. Table 2 shows the medical conditions for which GDPs prescribed prophylactic antibiotics before and during the audit. The only medical condition which showed a marked reduc-

Table 2 The medical conditions and the number of prescriptions for which GDPs prescribed antibiotics before and during audit

\begin{tabular}{lll}
\hline Medical condition & $\begin{array}{l}\text { No of prescriptions } \\
\text { before the audit }\end{array}$ & $\begin{array}{l}\text { No of prescriptions } \\
\text { during the audit }\end{array}$ \\
\hline Rheumatic fever & 81 & 70 \\
Murmurs & 58 & 28 \\
Valvular disease & 46 & 46 \\
Congenital heart defects & 11 & 6 \\
Coronary heart disease & 16 & 11 \\
Prosthetic joints & 8 & 1 \\
Radiotherapy/chemotherapy & 9 & 2 \\
Immunocompromised & 26 & 18
\end{tabular}

Table I The clinical conditions and the number of antibiotic prescriptions issued by GDPs before and during the audit, showing the percentage reduction in the number of prescriptions between the two periods

\begin{tabular}{llll}
\hline Clinical condition & $\begin{array}{l}\text { Number of } \\
\text { prescriptions } \\
\text { before the } \\
\text { audit }\end{array}$ & $\begin{array}{l}\text { Number of } \\
\text { prescriptions } \\
\text { during the } \\
\text { audit }\end{array}$ & $\begin{array}{l}\text { \% reduction } \\
\text { in number of } \\
\text { prescriptions }\end{array}$ \\
\hline Acute periapical infection & 906 & 507 & 44.0 \\
Acute periodontal abscess & 237 & 94 & 60.3 \\
Pericoronitis & 187 & 124 & 33.6 \\
Infected socket & 69 & 57 & 17.3 \\
Acute ulcerative gingivitis & 98 & 68 & 30.6 \\
Sinusitis & 20 & 6 & 70.0 \\
Post surgical procedure & 140 & 86 & 38.0 \\
During root canal therapy & 2 & 1 & 50.0 \\
After root canal therapy & 12 & 15 & $25.0 *$ \\
Periodontitis & 51 & 45 & 16.6 \\
Cellulitis & 5 & 1 & 80.0 \\
Pulpitis & 46 & 13 & 71.7 \\
Trismus & I & 0 & 100.0 \\
Gingivitis & 16 & 7 & 56.0 \\
Re-implantation of teeth & 0 & 1 & $100.0 *$ \\
Salivary gland infection & 0 & 2 & $200.0 *$ \\
Oral antral fistula & $\mathrm{I}$ & $\mathrm{I}$ & 75.0 \\
Others & 8 & 2 & \\
\hline
\end{tabular}

* \% Increase in the number of prescriptions between pre- and post-audit periods

tion $(51.7 \%)$ of prescriptions issued in the second data collection period related to murmurs. The other reasons for prescribing before and during the audit and the percentage reduction between the two data collection periods are shown in Table 3 . There was a reduction of $51 \%$ of prescriptions issued for localised swelling and $54 \%$ for pain following guidelines and the educational component.

\section{Statistical analysis}

Chi-square tests showed a significant change in the appropriateness of practitioners' prescribing practices between the two data collection periods when compared to national standards. ${ }^{14}$ There was a reduction in the number of prescriptions issued for diagnostic purposes $\left(\chi^{2}=16.70, \mathrm{df}=1, \mathrm{P}<0.001\right)$, because of pressure of time $\left(\chi^{2}=\right.$ 12.46, $\mathrm{df}=1, \mathrm{P}<0.001)$, patient expectation $\left(\chi^{2}=12.99 \mathrm{df}=1\right.$ $\mathrm{P}<0.001)$ and pain $\left(\chi^{2}=37.49, \mathrm{df}=1, \mathrm{P}<0.001\right)$, and patients presenting with localised swelling $\left(\chi^{2}=8.75, \mathrm{df}=1, \mathrm{P}<0.001\right)$.

Table 3 Reasons and the number of prescriptions for antibiotics prescribed by GDPs before and during the audit also showing the percentage reduction in the number of prescriptions between the two periods

\begin{tabular}{|c|c|c|c|}
\hline Reasons for prescribing & $\begin{array}{l}\text { Number of } \\
\text { prescriptions } \\
\text { issued before } \\
\text { the audit }\end{array}$ & $\begin{array}{l}\text { Number of } \\
\text { prescriptions } \\
\text { issued during } \\
\text { the audit }\end{array}$ & $\begin{array}{l}\% \text { reduction in } \\
\text { number of } \\
\text { prescriptions }\end{array}$ \\
\hline Localised fluctuant swelling & 724 & 354 & $5 I .1$ \\
\hline Gross diffuse swelling & 365 & 319 & 12.6 \\
\hline evidence of systemic spread & 179 & 177 & I.I \\
\hline $\begin{array}{l}\text { Pain } \\
\text { Prophylaxis due to medical }\end{array}$ & 1198 & 548 & 54.2 \\
\hline $\begin{array}{l}\text { history } \\
\text { Prophylaxis following surgical }\end{array}$ & 255 & 182 & 28.6 \\
\hline procedure & 140 & 86 & 38.5 \\
\hline Patient expectation & $12 \mid$ & 36 & 70.2 \\
\hline Pressure of time/workload & 86 & 22 & 74.4 \\
\hline Uncertainty of diagnosis & 80 & 16 & 80.0 \\
\hline $\begin{array}{l}\text { Treatment had to be delayed } \\
\text { Patient going on holiday/ in }\end{array}$ & 209 & 151 & 27.7 \\
\hline $\begin{array}{l}\text { case of problems } \\
\text { Failed local anaesthesia/ }\end{array}$ & 39 & 7 & 82.0 \\
\hline unco-operative patient & 26 & 14 & 46.1 \\
\hline
\end{tabular}




\section{Antibiotic regimens}

A significant improvement was seen between the two data collection periods. The prescribing of amoxycillin was significantly changed in the second data collection period and conformed more closely to national guidelines. Only $57.4 \%$ of prescriptions were at the recommended correct dose, frequency and duration before the guidelines were given. This increased to $70.5 \%$ following the audit $\left(\chi^{2}=36.79, \mathrm{df}=1, \mathrm{P}<0.001\right)$. A significant change was also seen in the prescribing regimen for metronidazole, with an increase from $25 \%$ correct prescriptions to $41.6 \%$ during the audit $\left(\chi^{2}=25.56\right.$, $\mathrm{df}=1, \mathrm{P}<0.001)$.

\section{Discussion}

The use of guidelines in audit to set standards is well recognised and it has been shown in medical practice that the publication of guidelines can improve prescribing. ${ }^{16}$ For antibiotic prescribing standards, dental practitioners rely on information in the Dental Practitioners Formulary (DPF). ${ }^{17}$ Unfortunately, the information available does not provide specific information on when to prescribe and what to prescribe in specific clinical situations and therefore could not be used effectively to set standards for audit. The guidelines given to the practitioners in the audit described were based on recently published guidelines produced by the Faculty of General Dental Practitioners. These guidelines were based on a review of all the available literature, best practice and consultation with many specialist dental societies. ${ }^{14}$ Even if a guideline is of high scientific quality, however, clinicians may still not follow it unless it is uncontroversial, specific, evidence based and requires no change to existing routine. ${ }^{18}$ It has been shown that guidelines alone are seldom of value ${ }^{19}$ but are more effective when linked with educational initiatives. ${ }^{20}$ The effectiveness of innovation techniques in persuading practitioners to accept guidelines has shown that opinion leaders $(100 \%)$ and audit with feedback (42\%) are more effective than formal continuing education. ${ }^{21}$

This investigation showed that this innovative audit, using guidelines and an educational component with feedback, was effective in reducing inappropriate antimicrobial use by changing GDPs' prescribing practices. It was evident from the pre-audit data that GDPs prescribed inappropriately, at times using the wrong antibiotic at the incorrect dose and duration and in clinical situations where there was little benefit to the patient. This confirmed the results of a questionnaire study carried out in general dental practice in England. ${ }^{4,5}$ There was a significant reduction in the number of inappropriate reasons for prescribing during the audit with fewer practitioners prescribing due to uncertainty of diagnosis, pressure of time, patient expectation, pain and localised swelling. There was also a reduction in the number of prescriptions for periodontal and periapical abscesses, pulpitis, infected sockets, sinusitis and following minor oral surgery. Whether these changes will be sustained requires further investigation after a suitable period of time. The importance of re-audit by GDPs cannot be overemphasized in order to continually improve patient care in this area of clinical practice.
The authors would like to thank the Cheshire LAPRAP for organising the audit, the practitioners for taking part, Dr M Martin and Dr L Longman for providing the educational programme, the audit facilitators who gave valuable assistance and Mrs R Pealing for inputting the data.

1 Secretaries of State for Health, Wales, Northern Ireland and Scotland. Working for patients. London: Her Majesty's Stationary Office, 1989.

2 Clinical Audit and Resource Group. The Interface between Clinical Audit and Management. Edinburgh: Scottish Office, 1994.

3 Palmer N, Martin M. An investigation of antibiotic prescribing by general dental practitioners: a pilot study. Prim Dent Care 1998; 5: 11-14.

4 Palmer N A O, Pealing R, Ireland R S, Martin M V. A study of prophylactic antibiotic prescribing in National Health Service general dental practice in England. Br Dent J 2000; 189: 43-46.

5 Palmer N A O, Pealing R, Ireland R S, Martin M V. A study of therapeutic antibiotic prescribing in National Health Service general dental practice in England. Br Dent J 2000; 188; 554-558.

6 Standing Medical Advisory Committee. The path of least resistance. London: Department of Health, 1998.

7 De Santis G, Harvey K J, Howard D, Mashford M L, Moulds R F. Improving the quality of antibiotic prescription patterns in general practice. The role of educational intervention. Med J Aust 1994; 160: 502-505.

8 Gyssens I C, Blok W L, van den Broek P J, Hekster Y A, van der Meer J W. Implementation of an educational program and an antibiotic order form to optimize quality of antimicrobial drug use in a department of internal medicine. Eur J Clin Microbiol Infect Dis 1997; 16: 904-912.

9 Zwar N, Wolk J, Gordon J, Sanson-Fisher R, Kehoe L. Influencing antibiotic prescribing in general practice: a trial of prescriber feedback and management guidelines. Fam Pract 1999; 16: 495-500.

10 Swann R A, Clark J. Antibiotic policies-relevance to general practitioner prescribing. Family Health Services Authority, Great Britain. J Antimicrob Chemother 1994; 33 (Suppl A): 131-135.

11 Steed M, Gibson J. An audit of antibiotic prescribing in general dental practice. Prim Dent Care 1997; 4: 66-70.

12 Muthukrishnan A, Walters H, Douglas P S. An audit of antibiotic prescribing by general practitioners in the initial management of acute dental infection. Dent Update 1996; 23: 316-318.

13 Packwood T. Clinical audit in four therapy professions:results of evaluation. London: The Royal Society of Medicine Press Ltd, 1995.

14 Faculty of General Dental Practitioners (UK), Royal College of Surgeons, England. Adult Antimicrobial prescribing in primary care for general dental practitioners, 2000.

15 SPSS for Windows Base Version. 9.0.0 version ed. Chigaco IL 60611: SPSS Inc, 1998.

16 Harvey K, Stewart R, Hemming M, Moulds R. Use of antibiotic agents in a large teaching hospital. The impact of Antibiotic Guidelines. Med J Aust 1983; 2: 217-221.

17 Dental Practitioners Formulary 1998-2000, British National Formulary No36. London: The Royal Pharmaceutical Society of Great Britain and the British Medical Association.

18 Grol R, Dalhuijsen J, Thomas S, Veld C, Rutten G, Mokkink H. Attributes of clinical guidelines that influence use of guidelines in general practice: observational study. BMJ 1998; 317: 858-861.

19 Freemantle N, Harvey E, Grimshaw J M, Wolf F, Bero L, Grilli R et al. The effectiveness of printed educational materials in changing the behaviour of health care professionals.In:Cochrane collaboration. In Issue 3 ed. Oxford: Cochrane Library; 1996.

20 Grimshaw J M, Russell I T. Achieving health gain through clinical guidelines II: Ensuring guidelines change medical practice. Qual Health Care 1994; 3: 45-52.

21 Davis D A, Thomson M A, Oxman A D, Haynes R B. Changing physician performance. A systematic review of the effect of continuing medical education strategies. JAMA 1995; 274: 700-705. 